\title{
A INSTITUCIONALIZAÇÃO DO NÚCLEO DE ESTUDOS E PESQUISAS EM GÊNERO E SEXUALIDADE NO IFNMG: RELATOS DE EXPERIÊNCIA
}

\author{
Ana Paula Quintino Rocha ${ }^{1}$ \\ Maria Aparecida Colares Mendes ${ }^{2}$ \\ DOI: https://doi.org/10.36524/profept.v5i2.743
}

\begin{abstract}
Resumo
A inserção da temática de gênero e sexualidade nas políticas educacionais é marcada por disputas que, historicamente, se refletem em avanços e recuos na formação voltada para o respeito e para o reconhecimento da diversidade sexual e de gênero na escola e na sociedade como um todo. Nesse sentido, este texto apresenta relatos de experiência quanto à institucionalização do Núcleo de Estudos e Pesquisas em Gênero e Sexualidade (NEPGS) no Instituto Federal de Educação, Ciência e Tecnologia do Norte de Minas Gerais (IFNMG). Foi proposta como questão central deste artigo a seguinte pergunta: de que forma delineou-se o processo de institucionalização do NEPGS no IFNMG? O objetivo é traçar o percurso histórico referente ao processo de regulamentação do NEPGS, por meio de relatos de experiência fornecidos por educadoras que atuaram nas etapas de concepção do núcleo, desde as primeiras discussões até a sua institucionalização no IFNMG. Optou-se por uma abordagem qualitativa, sendo o percurso metodológico baseado na narrativa coletada a partir de entrevista semiestruturada, bem como de questionamentos feitos por meio de correio eletrônico para complementação dos dados; na análise de documentos pertinentes ao núcleo; e, ainda, em revisão bibliográfica. O itinerário teórico e metodológico permitiu conhecer a temática e o início da trajetória desse núcleo, o qual tem muito a contribuir nas discussões sobre gênero e sexualidade no IFNMG. Os relatos e as demais informações coletadas demonstraram que a institucionalização do NEPGS é um passo importante para uma educação que pretende a formação humana integral e politécnica, direcionada para a ampliação da cidadania por meio do reconhecimento da diversidade e do respeito às diferenças. Contudo, para a concretização dos propósitos do NEPGS, faz-se necessária a formação inicial e continuada de educadoras(es) nessa temática, o apoio dos campi no desenvolvimento das ações e, sobretudo, a superação das barreiras do preconceito e da discriminação, para a construção de uma sociedade justa e emancipada.
\end{abstract}

Palavras-chave: gênero; sexualidade; educação para a diversidade.

\section{THE INSTITUTIONALIZATION OF THE NUCLEUS OF STUDIES AND RESEARCH IN GENDER AND SEXUALITY AT IFNMG: EXPERIENCE REPORTS}

\begin{abstract}
The insertion of the thematic of gender and sexuality in educational policies is marked by disputes that, historically, are reflected in advances and setbacks in training aimed at respecting and recognizing sexual and gender diversity in school and society as a whole. In this sense, this text presents experience reports regarding the institutionalization of the Nucleus for Studies and Research in Gender and Sexuality (NEPGS) at the Federal Institute of Education, Science and Technology of Northern Minas Gerais (IFNMG). It was proposed as central question of this article the following question: In which way was the process of institutionalizing the NEPGS outlined in the IFNMG? The objective is to trace the historical path referring to the NEPGS regulation process, through experience reports provided by educators who worked in the nucleus conception stages, from the first discussions to their institutionalization in the IFNMG. We opted for a qualitative approach, being the methodological route based on the narrative collected from semi-structured interviews, as well as questions made by email to complement the data; in the analysis of documents relevant to the
\end{abstract}

\footnotetext{
${ }^{1}$ Mestre em Educação Profissional e Tecnológica pelo Programa de Mestrado em Educação Profissional e Tecnológica do Instituto Federal de Educação, Ciência e Tecnologia do Norte de Minas Gerais. E-mail: anapquintino@yahoo.com.br

${ }^{2}$ Doutora em Desenvolvimento Rural - Professora do Programa de Mestrado em Educação Profissional e Tecnológica do Instituto Federal de Educação, Ciência e Tecnologia do Norte de Minas Gerais. E-mail: cidacolares@ hotmail.com
} 
nucleus; and, still, in bibliographic review. The theoretical and methodological itinerary allowed knowing the thematic and the beginning of the trajectory of this nucleus, which has much to contribute to the discussions on gender and sexuality at the IFNMG. The reports and other information collected demonstrated that the institutionalization of NEPGS is an important step towards an education that intend the integral and polytechnic human training, directed towards the expansion of citizenship through the recognition of diversity and respect for differences. However, for the fulfillment of the NEPGS purposes, it is necessary initial and continuous training of educators in this thematic, the support of campuses in the development of actions and, above all, overcoming the barriers of prejudice and discrimination, for the building a just and emancipated society.

Keywords: gender; sexuality; education for diversity.

\section{INTRODUÇÃO}

O artigo ora apresentado aborda os passos que desencadearam na institucionalização do Núcleo de Estudos e Pesquisas em Gênero e Sexualidade (NEPGS) no Instituto Federal de Educação, Ciência e Tecnologia do Norte de Minas Gerais (IFNMG), desde as primeiras discussões até a sua formalização, mediante a publicação da Resolução Consup ${ }^{3} \mathrm{n}^{\circ} 70$, no dia 28 de novembro de 2019. A trajetória rumo à instituição do núcleo é descrita por meio dos relatos de experiência de duas educadoras que participaram das etapas desse processo.

Conforme as discussões apresentadas por Louro (2014), a escola, como instituição autorizada a disciplinar corpos e mentes, produz e reproduz diferenças e desigualdades entre os sujeitos que por ela são educados. Essa educação que segrega de forma dualista e hierarquizada os saberes para ricos e pobres também afirma e prescreve as formas de ser e de se relacionar dos indivíduos. Assim, as diferenças de gênero e sexuais são moldadas pela escola por símbolos, códigos e normativas que ditam o que é apropriado para o que se diz ser mulher ou ser homem (LOURO, 2014).

Inserido nesse contexto social e educativo encontra-se o IFNMG. Presente há mais de 10 anos em cidades do estado de Minas Gerais, o Instituto surgiu da junção entre a Escola Agrotécnica Federal de Salinas e o Centro Federal de Educação Tecnológica de Januária, a partir da reorganização da Rede Federal de Educação Profissional, Científica e Tecnológica (EPCT), aprovada pela Lei $\mathrm{n}^{\circ} 11.892$, de 29 de dezembro de 2008.

Abrangendo os Vales do Jequitinhonha e Mucuri, o Norte e o Noroeste de Minas, o IFNMG conta atualmente (em 2020) com 12 unidades de ensino, além de sua unidade administrativa na Reitoria. São 11 campi - sendo dois deles avançados -, nos municípios de Almenara, Arinos,

\footnotetext{
${ }^{3}$ Sigla para Conselho Superior. O Conselho Superior é o órgão máximo dentro do IFNMG, de caráter consultivo e deliberativo.
} 
Araçuaí, Diamantina, Janaúba, Januária, Montes Claros, Pirapora, Porteirinha, Salinas e Teófilo Otoni, além de um Centro de Referência em Formação e Educação a Distância (IFNMG, 2018).

Alicerçado em um projeto de política educacional que se compromete a oferecer uma educação pública, gratuita e de qualidade nas diferentes modalidades de ensino, sejam elas de nível superior, básica e profissional, o IFNMG se propõe a viabilizar a educação profissional e tecnológica orientada para a formação omnilateral e politécnica, ou seja, uma formação humana que, articulada ao mundo do trabalho, promova o pensamento crítico e autônomo, especialmente das chamadas minorias sociais, tendo como horizonte a superação das injustiças sociais (FRIGOTTO, 2018).

No contexto desse projeto que busca romper as desigualdades e a dualidade estrutural encontra-se inserida a política de educação inclusiva e para a diversidade, que perpassa as atividades de ensino, pesquisa e extensão, por meio de ações formativas que subsidiem o acolhimento das diferenças em prol da defesa dos direitos humanos, a não discriminação e o respeito à diferença, entre outros princípios. No âmbito dessa política, destaca-se o trabalho da Diretoria de Assuntos Estudantis e Comunitários (DAEC), instituída em outubro de 2016 como órgão responsável pelas políticas e diretrizes relativas a programas, projetos e atividades que proporcionem a democratização de acessos e permanência dos discentes em seus estudos. Essas ações deverão ser articuladas entre a DAEC, o ensino, a pesquisa e a extensão, objetivando a redução da desigualdade social e a melhoria da qualidade de vida das(os) estudantes (IFNMG, 2018), o que propicia a permanência dos educandos na instituição e contribui para a redução dos índices de evasão.

A diretoria é composta pelo Núcleo de Assuntos Estudantis e Comunitários (NAEC) e pelo Núcleo de Ações Inclusivas (NAI), desenvolvendo projetos, programas e atividades em conjunto com os Núcleos de Estudos, Pesquisas e Extensão Afro-Brasileiros e Indígenas (NEABI) e os Núcleos de Atendimento às Pessoas com Necessidades Específicas (NAPNE) de cada um dos campi.

Inquietações advindas de educadoras(es) e estudantes a respeito da ampliação das discussões sobre diversidade sexual e de gênero suscitaram as primeiras articulações para a formalização do Núcleo de Estudos e Pesquisas em Gênero e Sexualidade (NEPGS). Partindo desse contexto de criação do NEPGS, foi proposta como questão central deste artigo a seguinte pergunta: de que forma delineou-se o processo de institucionalização do NEPGS no IFNMG?

Como objetivo, buscou-se traçar o percurso histórico referente ao processo que envolve a regulamentação do NEPGS, por meio de relatos de experiência fornecidos por educadoras que 
atuaram nas etapas de concepção do núcleo, desde as primeiras discussões até a sua institucionalização no IFNMG.

A metodologia utilizada teve como enfoque uma abordagem qualitativa, que buscou, mediante entrevista semiestruturada e informações encaminhadas por correio eletrônico, compreender as subjetividades das experiências compartilhadas por educadoras, em diálogo com as(os) seguintes autoras(es) que deram sustentação teórica ao estudo: Butler (2019); Foucault (2019); Louro (2014, 2019); Junqueira (2009); Frigotto (2018); Freire (1996); Mendes (2013); Vianna e Unbehaum (2016).

Este artigo organiza-se em quatro partes. A primeira é composta por esta introdução, em que se faz uma breve contextualização e problematização do tema, e apresentam-se os propósitos da pesquisa. Na segunda parte são descritos os percursos metodológicos estabelecidos. Na terceira, são apresentados os resultados e discussões que descrevem a trajetória do NEPGS, dos primeiros passos a sua aprovação em âmbito institucional, bem como os desafios para a materialização desse núcleo nos campi e sua importância para uma política de reconhecimento da diversidade sexual e de gênero. Na quarta parte são expressas as considerações finais referentes aos relatos de experiência compartilhados sobre a emergência do NEPGS.

\section{PERCURSO METODOLÓGICO}

A metodologia deste estudo está amparada pela abordagem qualitativa, em que se busca relacionar o mundo real e os sujeitos por meio de suas histórias, aspirações, crenças, valores e atitudes, para posterior interpretação dos fenômenos e atribuição de significados do universo empírico. Para tanto, recorremos às orientações das obras de Ludke e André (1986) e Bogdan e Biklen (1994) sobre a instrumentalização para uma investigação qualitativa.

Trata-se de relatos de experiência, que pretendem descrever as ações vivenciadas por educadoras no contexto da institucionalização do Núcleo de Estudos e Pesquisas em Gênero e Sexualidade (NEPGS) no IFNMG, tendo como enfoque a sensibilização para a concretização de uma educação voltada à diversidade sexual e de gênero, visando à ampliação da cidadania.

Os dados foram coletados com educadoras que exercem atividades relacionadas a assuntos estudantis e comunitários no IFNMG mediante entrevista semiestruturada, além de questionamentos feitos por meio de correio eletrônico para complementação das informações. Nomeamos as participantes da pesquisa com as codificações Tec1 e Tec2, que identifica cada sujeito entrevistado, a fim de manter em sigilo suas identidades. 
A entrevista semiestruturada admite um diálogo com maior flexibilidade, por não seguir um esquema rígido de perguntas (LUDKE; ANDRÉ, 1986), o que permitiu que a pesquisadora fizesse adaptações em seu roteiro. A conversa foi gravada e, posteriormente, transcrita para análise e discussão dos resultados.

A entrevista foi realizada com Tec1, que relatou como vivenciou sua experiência quanto à formalização do NEPGS, desde as primeiras discussões que levaram à idealização do núcleo, perpassando pelos objetivos e desafios, e ainda ressaltou a importância da concretização do núcleo em todos os campi do IFNMG.

Vale salientar que, previamente à realização da entrevista, a participante autorizou sua gravação em áudio e assinou o Termo de Consentimento Livre e Esclarecido (TCLE), que trazia os propósitos da pesquisa, seus riscos e benefícios, bem como a preservação do sigilo da identidade da entrevistada.

Contamos também com a colaboração da educadora Tec2, igualmente atuante nas discussões do NEPGS e que prontamente respondeu aos questionamentos sobre o núcleo, por meio de correio eletrônico, entre os dias 10 e 12 de maio de 2020.

Para contextualização dos marcos regulatórios do IFNMG referentes à política institucional para a diversidade sexual e de gênero, optamos pela análise documental. Nesse sentido, para coleta de dados secundários recorremos ao Regulamento do Núcleo de Estudos e Pesquisas em Gênero e Sexualidade (NEPGS), ao Estatuto e aos Regimentos do IFNMG, bem como aos Planos de Desenvolvimento Institucional (PDI) do Instituto, disponibilizados em sítios oficiais, que forneceram informações sobre a caracterização do locus da pesquisa e do núcleo em questão.

Utilizamo-nos da revisão bibliográfica para a construção do referencial teórico. Para abordar gênero e diversidade sexual parte-se da abordagem em interface com a teoria pós-crítica, enquanto as discussões no campo da educação profissional são articuladas à teoria crítica. $\mathrm{O}$ emprego dessas distintas teorias justifica-se pela possiblidade do diálogo entre elas no sentido de que ambas reconhecem o sujeito como legítimo cidadão de direito, independente de gênero e orientação sexual. Assim, a revisão bibliográfica foi embasada em teóricas(os) estudiosas(os) da temática de gênero, sexualidade e educação, como: Butler (2019), Foucault (2019), Louro (2014, 2019), Junqueira (2009), Vianna e Unbehaum (2016) nas concepções relacionadas à temática de gênero e sexualidade; Frigotto (2018), Freire (1996), Mendes (2013) nas reflexões sobre educação, educação profissional e cidadania.

\section{RESULTADOS E DISCUSSÃO}




\section{Provocações iniciais}

O artigo apresenta relatos de experiência de duas educadoras, identificadas sob as codificações de Tec1 e Tec2.

O relato de Tec1 foi dado por meio de entrevista na reitoria do IFNMG, no dia 20 de fevereiro de 2020, e teve duração de uma hora e 24 minutos. Inicialmente, a entrevistada Tec1 se apresentou e, quando questionada por esta pesquisadora, demonstrou dificuldade em responder qual seria sua identidade de gênero e orientação sexual, chegando a indagar: "feminino que a gente fala?’. Mas, após titubear diante da pergunta, respondeu identificar-se como mulher heterossexual.

Não é raro as pessoas desconhecerem ou fazerem confusão quanto à diferença entre identidade gênero e identidade sexual ou quanto à distinção entre gênero e sexualidade, visto que, conforme Louro (2014), as identidades de gênero e sexual estão profundamente interligadas. Segundo a autora, as identidades sexuais são vivenciadas de diversas formas e se constituem a partir de como a pessoa exerce a sua sexualidade em relação a outra pessoa - ela pode vivenciar prazeres e desejos com indivíduos que se identificam com o mesmo gênero que lhe foi designado em seu nascimento e/ou com gênero diferente do seu.

Para Butler (2019), as identidades são performativamente constituídas no tempo e no espaço e, dessa forma, o gênero é uma identidade dada por uma temporalidade social, portanto instável e fabricada por meio de uma repetição estilizada de atos. Sobre essa instabilidade das identidades, Louro (2019, p.13) explica que "somos sujeitos de identidades transitórias e contingentes. Portanto, as identidades sexuais e de gênero (como todas as identidades sociais) têm o caráter fragmentado, instável, histórico e plural." A autora ainda fala sobre as redes de poder imbricadas na sociedade, que moldam essas identidades, instaurando desigualdades, hierarquias e a heteronormatividade compulsória.

Tec1 é técnica-administrativa em educação do IFNMG, onde exerce atividades relacionadas a assuntos estudantis e comunitários, assessorando na regulamentação e implementação dos programas referentes à Política de Assistência Estudantil do IFNMG.

Perguntada sobre os motivos que levaram à institucionalização do NEPGS, Tec1 relata que a ideia surgiu a partir das demandas de alguns campi que já promoviam discussões em grupos de pesquisas e de extensão e em eventos que abordavam questões sobre gênero e sexualidade, entre eles o campus Salinas, o campus Pirapora e o campus Januária, conforme cita ela. A servidora lembra também que, mesmo antes da formação do núcleo, o assunto era tratado nos contextos de 
sala de aula por algumas/alguns docentes e pelos setores de assuntos estudantis e de inclusão dos campi, mesmo que de forma ainda incipiente.

Segundo a entrevistada, outras provocações que impulsionaram a existência do núcleo foram as ações realizadas no Seminário de Educação Profissional e Tecnológica Inclusiva (SEPTI), evento que acontece anualmente desde 2014 no IFNMG e que, a partir de 2016, conta com a colaboração da DAEC. A Diretoria, em parceria com o campus eleito para sediar o evento, desenvolve atividades sobre diversidade, preconceito e políticas de inclusão social.

Dentro da programação do SEPTI, de acordo com Tec1, procura-se tratar sobre políticas de inclusão para os diversos tipos de marcadores sociais, sejam eles de raça, classe social, gênero, orientação sexual, pessoas com deficiência, enfim, todas aqueles grupos vistos como minorias. Assim, são proporcionadas atividades e debates sobre diversidade sexual e de gênero em mesas redondas, oficinas, palestras, divulgando-se projetos de extensão e pesquisas de estudantes e educadoras(es). A partir dessas ações, Tec1 relata que as pessoas interessadas no estudo da temática de gênero e sexualidade começaram a reivindicar a normatização das discussões sobre a temática em âmbito de política interna do IFNMG, surgindo, então, as primeiras proposições para a criação do NEPGS.

Ainda dialogando com Tec1, a educadora relatou que outras questões inspiraram a regularização do Núcleo:

nós fomos recebendo a demanda de algumas unidades em torno disto e também pela necessidade de melhorar a discussão nesta temática, porque é um tema transversal e que pode gerar preconceito e constrangimento. Sabemos também de situações nas quais foram relatados casos de depressão e ansiedade por estas questões (TEC1).

Sobre situações de preconceito e discriminação nas escolas, apontadas como motivadores para a constituição do NEPGS, Tec1 relata que, durante o seu exercício no IFNMG, em nenhum momento testemunhou casos de violência relacionados a questões de gênero e sexual na instituição. No entanto, a entrevistada acredita que existe um preconceito velado e afirma que outras pessoas da comunidade escolar revelaram a ela a existência desses tipos de violência; cita ainda que esse tema é, inclusive, objeto de pesquisa de um estudante do campus Januária, que justifica seus estudos devido a ocorrências desses tipos de preconceito e de discriminação na instituição. Tec1 ainda se refere a um projeto, desenvolvido por uma docente, que acolhe estudantes que sofrem por diversos motivos, sendo um deles os conflitos internos causados por uma autoaceitação em ser uma pessoa não heterossexual. 
As declarações acima referem-se às práticas de preconceito e discriminação que, historicamente, atravessam a sociedade, oprimindo identidades que desestabilizam a suposta linearidade da sequência sexo-gênero-desejo (BUTLER, 2019). As escolas, como instituições configuradas, ao mesmo tempo, como reprodutoras e transgressoras de normas e padrões sociais relacionados às vivências sexuais e de gênero, não escapam a essas opressões que ditam as fronteiras das identidades, manifestando nesses espaços educativos as mais variadas formas de violências, visíveis e ocultas. Nessa perspectiva, Junqueira (2009) afirma que:

A escola configura-se um lugar de opressão, discriminação e preconceitos, no qual e em torno do qual existe um preocupante quadro de violência a que estão submetidos milhões de jovens e adultos $\mathrm{LGBT}^{4}$ - muitos/as dos/as quais vivem, de maneiras distintas, situações delicadas e vulneradoras de internalização da homofobia, negação, autoculpabilização, autoaversão. E isso se faz com a participação e a omissão da família, da comunidade escolar, da sociedade e do Estado (JUNQUEIRA, 2009, p. 15).

\title{
A institucionalização do Núcleo de Estudos e Pesquisas em Gênero e Sexualidade (NEPGS)
}

As primeiras articulações para a formalização em âmbito institucional de um núcleo que pudesse respaldar as atividades educativas voltadas à diversidade sexual e de gênero em cada campus do IFNMG começaram em 2018, conforme expõe Tec1 em seu relato:

\begin{abstract}
As discussões para a formação do núcleo iniciaram no final de 2018, porque víamos que tinha demanda dos campi que já possuíam ações específicas. Nós fomos ao comitê de ensino e fizemos a discussão e eles acharam interessante. E aí solicitamos que fosse encaminhado o nome de alguém que já fizesse este tipo trabalho no campus, como Januária e Pirapora, que já tinha gente à frente, ou a indicação de alguma outra pessoa. Nós lançamos a discussão e começamos a trabalhar em torno da minuta. Tivemos algumas reuniões procurando trazer de cada campus servidores com o perfil para trabalhar ou que já estivessem desenvolvendo algum projeto. Então, os campi já vinham manifestando algumas ações neste sentido, porque nós sabemos que há relatos de preconceito nestas unidades. E aí nós sentimos a necessidade de institucionalizar, de regulamentar e, ao fazer isto, nós incentivamos e estimulamos para que todas as unidades façam estas discussões e que tenham este núcleo nos seus campi (TEC1).
\end{abstract}

A princípio, de acordo com Tec1, houve uma aproximação entre a DAEC e membros da Pró-Reitoria de Ensino, para tratarem sobre os direcionamentos da criação do núcleo; no entanto, no decorrer do processo decidiu-se que os encaminhamentos para a formalização do NEPGS seriam

\footnotetext{
${ }^{4}$ LGBT é a sigla que se refere à população de lésbicas, gays, bissexuais, transgêneros e outras orientações sexuais, identidades e expressões de gênero. A sigla pode ser encontrada com o acréscimo de letras formando outros acrônimos, como LGBTIQ, que inclui pessoas intersexos e identidades queer. Com o objetivo de abranger outras orientações sexuais, identidades e expressões de gênero o símbolo + é acrescentado à sigla LGBT, formando outras variações (LGBT+, LGBTI+, LGBTQI+, dentre outras).
} 
conduzidos pelo Núcleo de Ações Inclusivas da Diretoria de Assuntos Estudantis e Comunitários (NAI/DAEC), vinculado à Reitoria.

Com o apoio de agentes que percebiam a relevância da abordagem desses temas para o reconhecimento da diversidade sexual e de gênero e para o enfrentamento à discriminação, a etapa seguinte reuniu servidoras(es) interessadas(os) de cada campus para compartilhar experiências bem como capacitar as(os) educadoras(es) que já tivessem uma sensibilidade e disposição para fazer parte do NEPGS.

No dia 15 de abril de 2019, ocorreu na reitoria do IFNMG a primeira reunião para capacitação de membros do NEPGS. A capacitação teve duração de oito horas e contou com a presença da diretora da DAEC, integrantes da referida diretoria, docentes de alguns campi, um estudante do campus Januária e pessoas convidadas, como esta pesquisadora que escreve. A DAEC convidou docentes da Universidade Estadual de Montes Claros (Unimontes) que pesquisam sobre gênero e sexualidade. Elas(es) apresentaram conceitos, indicaram bibliografias, compartilharam experiências sobre grupos de debate, estudos e pesquisas sobre a temática e falaram da importância, possibilidades e desafios da abordagem de gênero e sexualidade no contexto escolar.

A equipe da DAEC, envolvida na criação do NEPGS, passou por outros momentos de formação, ao longo do ano de 2019, em seminários e palestras, entre eles o I Seminário Efeitos de Gênero, organizado pela Unimontes, e o Agosto Lilás, evento ocorrido no IFNMG com palestras sobre o combate à violência contra as mulheres.

Após os momentos de formação no decurso do ano de 2019, a proposta para a constituição do NEPGS foi apresentada aos órgãos colegiados do Instituto. Segundo informação de Tec2 as(os) gestoras(es) do Colégio de Dirigentes apoiaram a criação e, ainda, elogiaram os propósitos do núcleo. Com a concordância das(os) gestoras(es), uma portaria foi gerada para a nomeação das(os) representantes dos campi interessados e de integrantes da DAEC, encarregados da elaboração do Regulamento do NEPGS.

Aconteceram reuniões por videoconferência com as pessoas nomeadas, para tratar da minuta do Regulamento; contudo, Tec1 admite que nem todos os campi se faziam presentes e acrescenta que, em algumas reuniões, o quórum era bastante reduzido em relação ao número de unidades do IFNMG. A fala de Tec1 sinaliza que houve uma certa inércia por parte de educadoras(es) de alguns campi do IFNMG quanto à constituição do núcleo, o que pode indicar que ainda há uma dificuldade na abordagem dessas temáticas.

A opção pela inércia diante da temática que envolve questões de gênero e sexualidade no contexto escolar é alertada por Louro (2014) como possível escolha pelo silêncio, e essa ausência da 
fala pode indicar uma vontade de que as normas de gênero e sexual não sejam transgredidas. A autora, fazendo referência ao não dito, chama a atenção para os efeitos dessa espécie de ocultação, dizendo que "a negação dos(as) homossexuais no espaço legitimado da sala de aula acaba por confiná-los às 'gozações' e aos 'insultos' dos recreios e dos jogos, fazendo com que, deste modo, jovens gays e lésbicas só possam se reconhecer como desviantes, indesejados ou ridículos" (LOURO, 2014, p. 72).

A minuta do NEPGS, logo elaborada, foi encaminhada aos órgãos colegiados, que fizeram ponderações técnicas acerca de termos constantes no documento e solicitaram uma revisão com auxílio do relator, o que fez com que houvesse uma delonga para a sua aprovação final.

Acatada a minuta do Regulamento, o NEPGS foi oficialmente institucionalizado no IFNMG por meio da Resolução Consup n ${ }^{\circ} 70$, do dia 28 de novembro de 2019, que aprovou a possibilidade de criação dos núcleos nos campi, ficando a critério de cada um a sua instauração.

De acordo com Tec1, o núcleo foi pensado para ser propositivo, consultivo e de assessoramento, visando incentivar e promover ações de ensino, pesquisa e extensão relacionadas a gênero e sexualidade nos campi do IFNMG. A educadora fala da principal finalidade do NEPGS, a qual transcrevemos a seguir:

propor políticas de educação para a diversidade e também subsidiar a discussão acerca das temáticas, porque quando se tem um núcleo específico para o tema fortalece a discussão e fomenta as pesquisas. Então, o NEPGS tem esta intenção de promover a transversalidade entre o ensino, a pesquisa, a extensão e atuar na difusão da temática e, principalmente, de difundir a formação de servidores de cada unidade, porque é algo que não tem como fugir no cotidiano. Vira e mexe pode ter uma situação em que o aluno pode provocar, pode questionar, então é algo que não pode ser banalizado. A gente vê que na sociedade ainda tem muitas piadinhas em relação a isto, tratando com termos perjorativos, então a insituição, por ser uma instituição de educação, não pode permitir este tipo de situação, porque as pessoas devem ser tratadas com respeito (TEC1).

\section{NEPGS nos campi: resistir para existir}

Nessa trajetória de construções para uma política interna institucionalizada direcionada à diversidade sexual e de gênero do IFNMG, alguns obstáculos foram superados e outros desafios foram lançados. Isso pôde ser percebido nas falas de Tec1, que expôs algumas resistências por parte de gestoras(es) que questionaram a relevância de se criar um núcleo específico para tratar sobre essa temática. A entrevistada relata:

O NEPGS teve resistência por causa dos termos que assustavam um pouco os gestores, no sentido de qual seria o poder do núcleo, seria de execução, se teria que ter coordenador. 


\begin{abstract}
Mas acho que também tem a questão do preconceito, sabe, de assim: "mas núcleo de gênero, mas para que isto?". Eu percebi isto em alguns gestores, esta questão de questionar a necessidade de criação deste núcleo, alguns tiveram esta reação. (...) Esta questão do preconceito velado em relação à temática, ela existe, só que as pessoas, muitas vezes, não manifestam abertamente. Elas vão manifestar fazendo um questionamento, transparecendo que é algo estranho, que está fora do padrão. Tivemos questionamentos que em outro documento não aconteciam de uma forma tão clara (TEC1).
\end{abstract}

Em direção oposta a esses questionamentos de objeção ao NEPGS, Louro (2014) propõe às(ao)s educadoras(es) engendrarem outros tipos de questionamentos. A autora diz que é preciso colocar em questão de forma crítica e reflexiva os currículos escolares, os procedimentos de ensino, as teorias da educação, as práticas pedagógicas, os materiais didáticos, as relações sociais que se fazem presente na escola, de forma a ampliar o olhar sobre as regras que pretendem definir e controlar os sujeitos generificados, sexuados e sexualizados.

A formação continuada sobre os temas gênero e sexualidade também foi apontada por Tec1 como algo que tem que ser fomentado, para um melhor entendimento das(os) educadoras(es) sobre a temática. Segundo ela, grande parte das(os) profissionais da educação no IFNMG não estão preparadas(os) para educar para essas diversidades ou possuem alguma dificuldade na tratativa do tema, possivelmente por não terem formação no assunto:

\begin{abstract}
a gente sente que é um tema que está meio que à margem das discussões, de momento de formação, principalmente para o corpo docente e o corpo de servidores de uma forma geral, tanto terceirizados como os servidores da instituição, e também para os alunos, pois acaba que, quando não se tem uma equipe com formação específica, que está preparada, os alunos também sofrem com esta falta de formação. (...) É algo que a gente precisa estudar mais, até mesmo com os servidores aqui da gestão (TEC1).
\end{abstract}

A trajetória da construção e consolidação de políticas educacionais voltadas para a diversidade sexual e de gênero é marcada por conflitos entre os setores mais progressistas e conservadores da sociedade brasileira. Somente a partir de 1970 os debates sobre gênero e sexualidade ganharam uma certa visibilidade nos currículos escolares, e isso certamente refletiu na formação de educadoras(es). Nas últimas décadas, entretanto, nota-se que houve uma busca pela reparação dessa ausência na formação inicial dos profissionais da educação mediante iniciativas localizadas de formação continuada, promovidas por instituições de educação e pesquisa e por movimentos sociais (VIANNA; UNBEHAUM, 2016).

A formação de educadores para a diversidade sexual e de gênero, seja ela inicial ou continuada, presencial ou à distância, é defendida por Vianna (2012) como um importante mecanismo de superação de ideias preconcebidas e de construção de novos conhecimentos e práticas. A autora afirma que essa formação deve não só abranger a perspectiva de gênero, mas 
envolver também as múltiplas dimensões que se desdobram na produção das desigualdades sociais, como as questões relacionadas à raça/etnia, classe, geração, entre outros marcadores sociais de desigualdade.

As integrantes da equipe da DAEC que fazem a articulação com os NEPGS nos campi participaram, ao longo de 2019, de capacitações sobre o tema; no entanto, Tec1 alega que há uma sobrecarga de atividades para essas servidoras que, além de atuarem em trabalhos relacionados a esse núcleo, ainda lidam com as demais políticas de inclusão, o que se torna um agravante para a efetividade das ações do NEPGS.

Tec2, que é uma servidora que atua nessas articulações entre a DAEC, na Reitoria, e os NEPGS, nos campi, informou que, até a data do dia 12 de maio de 2020, somente o campus Januária, o campus Salinas e o campus Pirapora haviam instituído o NEPGS, ou seja, menos da metade das unidades do IFNMG. Quanto aos demais campi, a educadora argumenta que "ficaram livres dentro da sua autonomia” para, quando julgarem necessário, instituí-lo.

Para Tec1, há uma dificuldade em se discutir gênero e sexualidade na escola, e isso é efeito de uma sociedade historicamente machista. Ela ainda destaca que "existe a questão de algumas pessoas falarem que não se pode falar sobre sexualidade para não incentivar", ou seja, há uma rejeição à abordagem do tema devido ao medo social que grupos conservadores da comunidade escolar possuem daquelas pessoas transgressoras da heteronormatividade.

Ao falar sobre seu processo formativo escolar e acadêmico, Tec1 relembra que em nenhum momento de sua formação houve esse tipo de discussão sobre identidade de gênero e orientação sexual e que, quando se falava em sexualidade, era numa perspectiva da biologia. Sobre essa perspectiva biológica das identidades, Butler (2019) faz reflexões sobre os mecanismos de poder produzidos historicamente por instituições - entre elas o Estado, a Igreja e a escola - que, através de uma retórica biologizante, perpetuam discursos de uma natureza humana implícita que estabiliza o gênero masculino/feminino e trata a heterossexualidade como adequada e "normal" e os outros tipos de identidades sexuais e de gênero como desviantes e "anormais".

Por esses motivos, Tec1 diz que essa ainda é uma temática marginalizada e que precisa ser tratada com mais seriedade e respeito, a partir do envolvimento de toda a comunidade do IFNMG. Sobre a importância do núcleo, Tec1 declara:

Eu acredito que, quando a gente traz esta questão do gênero e do respeito à diversidade, ajuda o ser humano a se conhecer e dá a possibilidade de respeitar o outro, a saber lidar com o outro, saber trabalhar em equipe, ter uma sabedoria no sentido da convivência na sociedade. (...) esta discussão ela precisa ser melhor tratada em nossas unidades para a gente poder ter uma relação humana melhorada, principalmente entre professor e aluno, 
porque as relações de poder, elas existem, né. Quanto mais a gente puder humanizar esta relação, fortalecer o diálogo e melhorar a cultura do respeito, é muito válido. Por isto que estes núcleos nas unidades são tão importantes. E ter também a formação para que as pessoas estejam dispostas a aprimorar sua prática. Neste sentido que a gente visualiza o NEPGS com um trabalho a médio e longo prazo para que fomente o interesse nesta temática para o aprimoramento da formação, principalmente a humana (TEC1).

\section{CONSIDERAÇÕES FINAIS}

Ao analisar e refletir sobre a experiência relatada, nota-se que o Núcleo de Estudos e Pesquisas em Gênero e Sexualidade surgiu a partir das provocações da comunidade escolar, especialmente de educadoras(es) e estudantes que perceberam a necessidade de uma discussão mais ampla sobre gênero e sexualidade no IFNMG. A constituição do núcleo é um caminho para intervenções que possam aprofundar essas questões, que são intencionalmente colocadas à margem por um projeto de sociedade estruturado em hierarquias e padrões.

O IFNMG é uma instituição educativa sustentada em princípios de respeito à vida e que visa à formação humana, politécnica e omnilateral. Dessa forma, a constituição de políticas internas para a diversidade sexual e de gênero, como é o caso do NEPGS, busca contribuir para que, de forma ativa e reflexiva, os silêncios sejam rompidos, preconceitos e discriminações enfrentadas e as diversas formas de existências reconhecidas para além do modelo imposto pela heteronormatividade.

As objeções de educadoras(es) quanto à relevância do NEPGS, relatadas por Tec1, levamnos à seguinte indagação: o que leva os campi a não terem ainda o NEPGS? Será que é somente a questão da capacitação das pessoas envolvidas no processo educativo nessa temática ou está por trás toda uma lógica de preconceitos e retrocessos de grupos conservadores que negam a importância de se tratar da diversidade sexual e de gênero?

Assim, faz-se necessário ressaltar que, não obstante a formalização do núcleo em âmbito institucional, é fundamental a participação direta dos campi para que, mesmo diante de sua autonomia, reconheçam a importância da implementação do núcleo para realizações de atividades de ensino, pesquisa e extensão que abordem questões sobre gênero e sexualidade, e, a partir dessas discussões, construa-se um ambiente educativo mais acolhedor. Todavia, percebe-se que, para a concretização dos propósitos de uma política para a diversidade sexual e de gênero, é preciso promover a formação inicial e continuada das(os) educadoras(es) nessa temática, haja vista que, como foi relatado, muitas(os) desconhecem as especificidades ou até mesmo possuem resistência quanto ao tema. 
É nessa perspectiva que o NEPGS se coloca como um importante espaço de intervenção para desnaturalizar mecanismos de poder que hierarquizam e oprimem os sujeitos da escola, especialmente as(os) estudantes, por questões de gênero e/ou sexualidade. Nas palavras de Paulo Freire (1996, p.110), "a educação é uma forma de intervenção no mundo"; como educadoras(es) devemos lutar contra e resistir às forças dominantes que insistem em nos silenciar, e o NEPGS pode ser um instrumento de luta por uma cidadania ampla e para a construção de um mundo mais justo e seguro para todas as pessoas.

\section{REFERÊNCIAS}

BOGDAN, R.; BIKLEN, S. Investigação qualitativa em educação: uma introdução à teoria e aos métodos. Porto: Porto Editora, 1994.

BUTLER, J. Problemas de gênero: feminismo e subversão da identidade. Tradução de Renato Aguiar. 17. ed. Rio de Janeiro: Civilização Brasileira, 2019.

FOUCAULT, M. História da sexualidade 1: A vontade de saber. Tradução de Maria Thereza da Costa Albuquerque e J. A. Guilhon Albuquerque. 8. ed. Rio de Janeiro/São Paulo: Paz e Terra, 2019.

FREIRE, P. Pedagogia da autonomia: saberes necessários à prática educativa. 24. ed. Rio de Janeiro: Paz e Terra, 1996.

FRIGOTTO, Gaudêncio. Indeterminação de identidade e reflexos nas políticas institucionais formativas dos IFs. In: . (Org.). Institutos Federais de Educação, Ciência e Tecnologia: relação com o ensino médio integrado e o projeto societário de desenvolvimento. Rio de Janeiro: UERJ, LPP, 2018. p. 125-150.

INSTITUTO FEDERAL DO NORTE DE MINAS GERAIS. Estatuto do IFNMG. Alterado pela Resolução Consup n ${ }^{\circ}$ 001, de 07 de fevereiro de 2018. Disponível em:

https://www.ifnmg.edu.br/docs-regulamentos. Acesso em: 04 jan. 2019.

INSTITUTO FEDERAL DO NORTE DE MINAS GERAIS. Regimento Geral do IFNMG. Alterado pela Resolução Consup n ${ }^{\circ}$ 002, de 07 de fevereiro de 2018. Disponível em: https://www.ifnmg.edu.br/docs-regulamentos. Acesso em: 04 jan. 2019.

INSTITUTO FEDERAL DO NORTE DE MINAS GERAIS. Regimento Interno dos Campi. Disponível em: https://www.ifnmg.edu.br/docs-regulamentos. Acesso em: 17 dez. 2018.

INSTITUTO FEDERAL DO NORTE DE MINAS GERAIS. Plano de Desenvolvimento Institucional - PDI IFNMG 2019-2023. Reitoria do IFNMG, 2018. Disponível em: https://www.ifnmg.edu.br/docs-planejamento. Acesso em: 24 out. 2019. 
Gerais. Julho, 2019. Disponível em: https://www.ifnmg.edu.br/nepgsifnmg. Acesso em: 04 fev. 2020.

JUNQUEIRA, R. D. Homofobia nas Escolas: um problema de todos. In: (Org.).

Diversidade Sexual na Educação: problematizações sobre a homofobia nas escolas. Brasília: Ministério da Educação, Secretaria de Educação Continuada, Alfabetização e Diversidade, UNESCO, 2009. p. 13-51. Disponível em:

http://www.clam.org.br/bibliotecadigital/uploads/publicacoes/1952 763 divesidadesexual.pdf. Acesso em: 23 mar. 2019.

LOURO, G. L. Gênero, sexualidade e educação: uma perspectiva pós-estruturalista. 16. ed. Petrópolis, RJ: Vozes, 2014.

LOURO, G. L. Pedagogias da sexualidade. In: (Org.). O corpo educado: pedagogias da sexualidade. Tradução de Tomaz Tadeu da Silva. 4. ed. Belo Horizonte: Autêntica Editora, 2019.

LUDKE, M.; ANDRÉ, M. Pesquisa em educação: abordagens qualitativas. São Paulo: EPU, 1986.

MENDES, M. A. C. Racionalidades, cidadania e desenvolvimento rural: a formação do técnico em agropecuária no Norte de Minas Gerais. Tese (Doutorado em Desenvolvimento Rural) Faculdade de Ciências Econômicas, Universidade Federal do Rio Grande do Sul, Porto Alegre, 2013.

VIANNA, Cláudia. Gênero, sexualidade e políticas públicas de educação: um diálogo com a produção acadêmica. Pro-Posições, Campinas, v. 23, n. 2, p. 127-143, 2012. Disponível em: https://www.scielo.br/pdf/pp/v23n2/a09v23n2. Acesso em: 22 abr. 2020.

VIANNA, C; UNBEHAUM, S. Contribuições da produção acadêmica sobre gênero nas políticas educacionais: elementos para repensar a agenda. In: CARREIRA, D. et al. Gênero e educação: fortalecendo uma agenda para as políticas educacionais. São Paulo: Ação Educativa, Cladem, Ecos, Geledés, Fundação Carlos Chagas. 2016. 